\title{
Salicylic Acid Biosynthesis in Plants
}

\author{
Hannes Lefevere, Lander Bauters and Godelieve Gheysen* \\ Department of Biotechnology, Faculty of Bioscience Engineering, Ghent University, Ghent, Belgium
}

Salicylic acid $(S A)$ is an important plant hormone that is best known for mediating host responses upon pathogen infection. Its role in plant defense activation is well established, but its biosynthesis in plants is not fully understood. SA is considered to be derived from two possible pathways; the ICS and PAL pathway, both starting from chorismate. The importance of both pathways for biosynthesis differs between plant species, rendering it hard to make generalizations about SA production that cover the entire plant kingdom. Yet, understanding SA biosynthesis is important to gain insight into how plant pathogen responses function and how pathogens can interfere with them. In this review, we have taken a closer look at how SA is synthesized and the importance of both biosynthesis pathways in different plant species.

\section{OPEN ACCESS}

Edited by:

Danièle Werck,

CNRS, UPR2357 Institut de Biologie

Moléculaire des Plantes (IBMP),

France

Reviewed by:

Thierry Heitz,

UPR2357 Institut de Biologie

Moléculaire des Plantes (IBMP),

France

Jürgen Zeier,

Heinrich Heine University Düsseldorf,

Germany

*Correspondence:

Godelieve Gheysen

godelieve.gheysen@ugent.be

Specialty section:

This article was submitted to

Plant Metabolism

and Chemodiversity,

a section of the journal

Frontiers in Plant Science

Received: 20 December 2019

Accepted: 06 March 2020

Published: 17 April 2020

Citation:

Lefevere $H$, Bauters $L$ and

Gheysen G (2020) Salicylic Acid

Biosynthesis in Plants.

Front. Plant Sci. 11:338.

doi: $10.3389 / f p / s .2020 .00338$
Keywords: salicylic acid biosynthesis, isochorismate synthase, phenylalanine ammonia-lyase, plant defense, pathogen infection

\section{INTRODUCTION}

Salicylic acid (SA) was reported to play a role in disease resistance in tobacco plants by White already in 1979 (White, 1979). Since then, the importance of SA in plant defense to biotic and abiotic stimuli has been well established. SA levels are known to increase in many pathosystems upon infection with viruses, fungi, insects, and bacteria (Ogawa et al., 2006; Kim and Hwang, 2014; Hao et al., 2018; Zhao et al., 2019), and exogenous SA treatment boosts the defense system of the host (Nahar et al., 2011; Wang and Liu, 2012; Tripathi et al., 2019; Zhang and Li, 2019). Plants overexpressing NahG, a salicylate hydroxylase degrading SA, are unable to accumulate SA upon pathogen infection and are impaired in their systemic acquired resistance (SAR), a broad-spectrum systemic resistance acquired after a primary infection (Lawton et al., 1995). Although SA is essential for SAR, it is probably not the mobile signal. SAR is orchestrated by a collaboration between SA and pipecolic acid (Hartmann and Zeier, 2019; Huang et al., 2020). Despite the importance of SA in plant defense, its biosynthesis is not fully understood. In this review paper, we have focused on SA biosynthesis in the dicot Arabidopsis thaliana and the monocot rice (Oryza sativa). Still, there are also some interesting observations made of other plants that we will touch on in this paper. For more detailed information regarding transport, perception, and signaling, we refer the reader to some recent reviews (Maruri-Lopez et al., 2019; Pokotylo et al., 2019; Zhang and Li, 2019).

\section{SA BIOSYNTHESIS AND METABOLISM IN PLANTS}

It is widely accepted that plants possess both an isochorismate synthase (ICS) and phenylalanine ammonia-lyase (PAL) pathway to synthesize SA, both starting from chorismate (Figure 1). However, not all enzymes catalyzing these pathways have been identified in plants. The importance of these pathways for the biosynthesis of SA varies in different plant species. In Arabidopsis, the ICS pathway is the most important, while the PAL pathway seems to be more important for SA 
accumulation in rice. Both pathways contributing equally is also a possibility, as is the case in soybeans. Furthermore, SA biosynthesis regulation can even be different within the plant. In rice, for example, the basal SA levels in shoots are much higher than in roots (Silverman et al., 1995; Duan et al., 2014).

Salicylic acid can undergo several modifications in the plant. Most of them cause SA to become inactive. When SA is glucosylated, SA glucoside (SAG) can be produced. This compound can be stored in the vacuole in large quantities (Dean et al., 2003). As a result of glucosylation by Salicyloyl glucose ester (SGE) is another SA sugar conjugate that can be formed in plants. Methylation increases the membrane permeability of SA and makes it more volatile. This derivative can be released from the plant and serves as a cue for plant-insect interactions (Snoeren et al., 2010). Another major modification is amino acid (AA) conjugation, possibly involved in SA catabolism (Mackelprang et al., 2017). Hydroxylation of SA results in 2,3and 2,5 dihydroxybenzoic acid (2,3-DHBA and 2,5 DHBA) (Dempsey et al., 2011). Recently, a glycosyltransferase has been identified that can convert MeSA to MeSA glucoside (MeSAG) (Chen et al., 2019).

\section{ICS PATHWAY IN PLANTS}

The first pathway for SA biosynthesis starts from chorismate, which is converted into isochorismate (IC) by ICS (Figure 1; Catinot et al., 2008; Abreu and Munne-Bosch, 2009; Hao et al., 2018). This pathway was first discovered in bacteria. In Pseudomonas species, SA is synthesized for the production of siderophore pseudomonine. The PmsCEAB gene cluster plays a key role in this biosynthesis (see Table 1). $P m s C$ shows high sequence similarity with ICS in $E$. coli, where this enzyme catalyzes the conversion of chorismate to IC (Mercado-Blanco et al., 2001). The PmsB gene encodes an isochorismate pyruvatelyase $(I P L)$ gene, which converts IC to SA. This means that $\mathrm{SA}$ is synthesized from chorismate in a two-step process in Pseudomonas.

The number of ICS homologs is limited within plant genomes, with the majority of the plants having one or two gene copies. The subsequent step was, until recently, presumed to be catalyzed by IPL, but this enzyme has only been discovered in bacteria (Mercado-Blanco et al., 2001). Two 2019 studies showed that SA synthesis via ICS in Arabidopsis differs from that in bacteria. Amino acid conjugation of IC, followed by spontaneous decomposition or enzymatic conversion, results in the formation of SA. The gene responsible, $P B S 3$, has been characterized in Arabidopsis but not in any other plants (Jagadeeswaran et al., 2007; Nobuta et al., 2007; Rekhter et al., 2019; Torrens-Spence et al., 2019).

The ICS pathway plays an important role in pathogeninduced SA accumulation in Arabidopsis (Nawrath and Metraux, 1999). The Arabidopsis genome contains two ICS homologs, AtICS1 and AtICS2 (Garcion et al., 2008). Garcion et al. (2008) demonstrated that SA accumulation, elicited by UV treatment, is severely impaired in ics 1 and ics 1 ics 2 mutants. These mutants show a $90 \%$ decrease in UV-induced SA levels in Arabidopsis leaves. However, ics 2 mutants show no significant difference in basal or UV-induced SA levels compared to WT plants. This suggests that AtICS1 is the main contributor for basal and UVinduced SA levels. Another study presents strong evidence for the importance of ICS1 in Arabidopsis. When AtICS1 is expressed in $N$. benthamiana, a much higher enzymatic activity is observed than for any other plant ICS tested, confirming the importance of ICS1 in Arabidopsis SA accumulation (Yokoo et al., 2018). The avrPphB SUSCEPTIBLE3 (PBS3) enzyme has recently been shown to be responsible for the conversion of IC to SA. Knockout mutants in the PBS3 gene show severely lowered SA and SAG levels, indicating its critical role in SA biosynthesis in Arabidopsis. PBS3 catalyzes the conjugation of IC and glutamate to produce isochorismate-9-glutamate. This compound can be converted by ENHANCED PSEUDOMONAS SUSCEPTIBILITY 1 (EPS1), an acyltransferase (Torrens-Spence et al., 2019), or spontaneously decompose into SA and 2-hydroxy-acryloyl-Nglutamate (Rekhter et al., 2019). However, pbs3 knock-out mutants, as opposed to ics1 mutants, still accumulate SA upon pathogen inoculation (Lee et al., 2007). Furthermore, eps1 knock-out mutations do not completely prevent SA biosynthesis (Torrens-Spence et al., 2019), suggesting that IC-derived SA biosynthesis is still not fully understood and that a PBS3/EPS1 independent pathway might be present. Since ICS is located in the plastid and PBS3 in the cytoplasm, IC needs to be transported out of the plastid. The ENHANCED DISEASE SUSCEPTIBILITY 5 (EDS5) protein, a MATE transporter, is thought to be responsible for this transport, and eds 5 mutants, formerly sid 1 mutants, show much lower levels of SA upon pathogen infection (Nawrath and Metraux, 1999; Nawrath et al., 2002).

In rice, ICS is a single copy gene. In contrast to Arabidopsis, there is relatively little evidence for the importance of the OsICS enzyme in SA biosynthesis. The transcription factor OsWRKY6 has been suggested to be responsible for SA accumulation by activating the OsICS gene (Choi et al., 2015). However, WRKY transcription factors regulate a multitude of defense-related genes, such as $P A L$, which could also be responsible for this increase in SA (Liu et al., 2005, 2018). Furthermore, it was shown that OsICS has a very low level of enzymatic activity compared to the Arabidopsis homolog (Yokoo et al., 2018). In addition, there is no published research associating OsICS with disease resistance in rice. In conclusion, the ICS pathway might not be the main route for SA production in rice.

\section{PAL PATHWAY IN PLANTS}

While the idea of the ICS pathway as a production route for SA in plants is relatively new and based on observations in bacteria, the importance of the PAL pathway has been known for much longer. While this pathway can be responsible for the biosynthesis of SA, it should be considered that PAL is an upstream enzyme that leads to many other possibly defense-related compounds (Dixon and Paiva, 1995). Chorismate mutase (CM) is a key enzyme in the biosynthesis of SA and is responsible for catalyzing the conversion of chorismate to prephenate (Figure 1). Most plant species have several CMs in their genome. It is, however, 


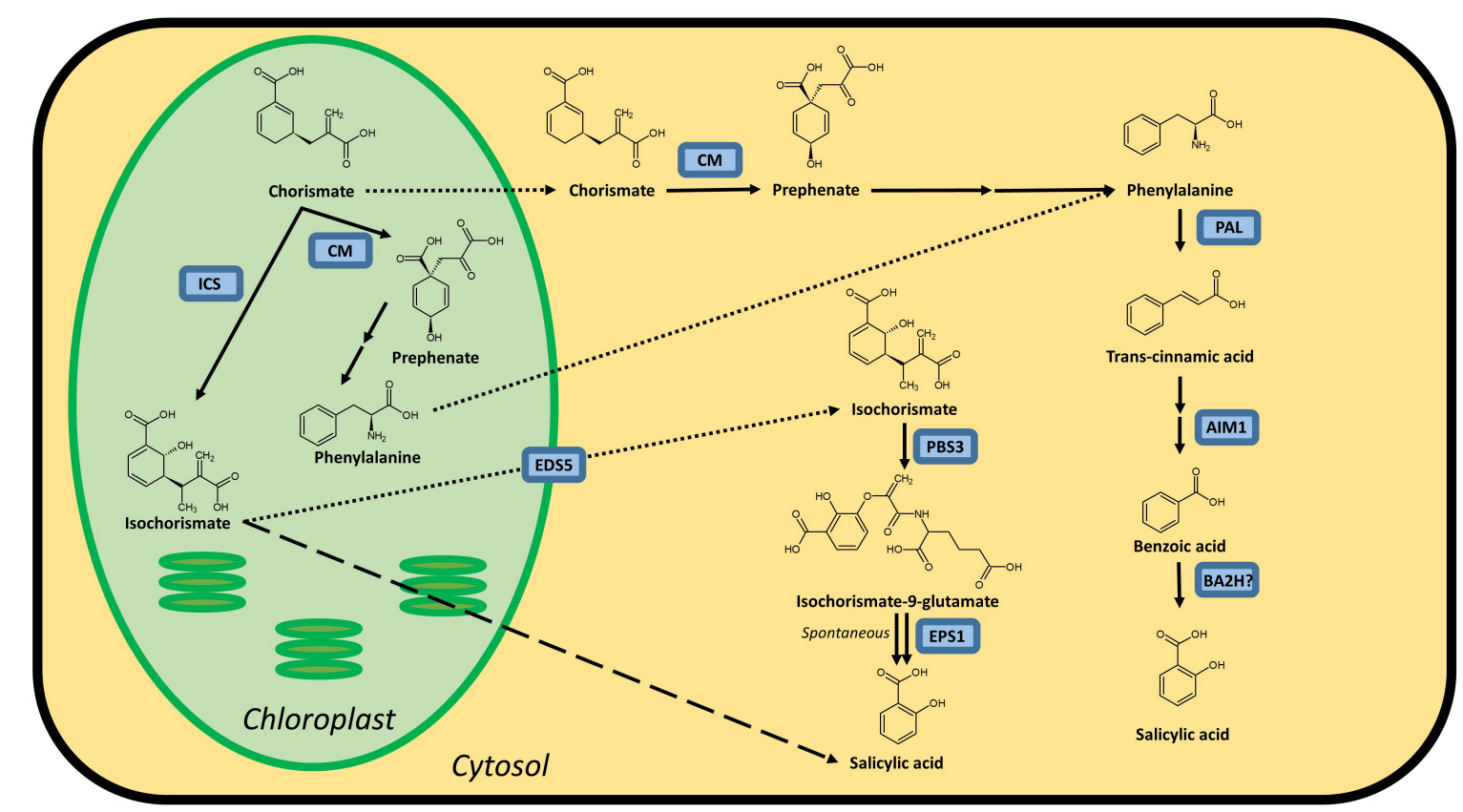

FIGURE 1 | Possible biosynthesis routes for SA in plants. Full lines are conversion steps, dotted lines are transport from chloroplast to cytosol, the dashed line is an alternative, unknown biosynthesis route. The question mark indicates an unidentified protein. It is unclear whether the steps leading up to phenylalanine are performed in the chloroplast or cytosol, or in both simultaneously, as there are chloroplastic and cytosolic CMs. Enzymes are indicated in blue and are abbreviated as follows: ICS, isochorismate synthase; CM, chorismate mutase; PAL, phenylalanine ammonia-lyase; AIM1, abnormal inflorescence meristem1; BA2H, benzoic acid 2-hydroxylase; EDS5, ENHANCED DISEASE SUSCEPTIBILITY 5; PBS3, avrPphB SUSCEPTIBLE3; EPS1, ENHANCED PSEUDOMONAS SUSCEPTIBILITY 1. In Arabidopsis, sid1 mutants are loss-of-function eds5 mutants, while sid2 mutants are loss-of-function ics1 mutants.

more relevant to consider the conversion steps that lead from phenylalanine (Phe) to SA (Figure 1), as the steps before this metabolite branch into many other biosynthetic routes. The enzyme PAL converts Phe into trans-cinnamic acid (tCA) and has been identified in many plant species. In most cases, PAL is only able to perform this single reaction. Yet, some have a secondary tyrosine ammonia-lyase (TAL) activity (Rosler et al., 1997; Cass et al., 2015; Barros et al., 2016). PAL genes are present in many copies in the genome and are differentially expressed between plant tissues, which makes generalization hard to come by Reichert et al. (2009). Mutant analysis in Arabidopsis has identified another key player in the PAL pathway: abnormal inflorescence meristem1 (AIM1), named after the phenotype of a knock-out plant (Richmond and Bleecker, 1999). AIM1 has been identified in Arabidopsis and rice and is a member of the multifunctional protein (MFP) family (Rylott et al., 2006; Arent et al., 2010). These play a major role in fatty acid metabolism and are also required for the metabolism of amino acids and hormones. AIM1 is able to catalyze the conversion of tCA into benzoic acid (BA). It functions as a beta-oxidation enzyme and thus has many more substrates than tCA, such as fatty acids. This makes knock-out plants in this gene complex to interpret, but nonetheless valuable for studies on SA biosynthesis and defense responses. The last step, converting BA into SA, is catalyzed by a presumed benzoic acid hydroxylase. This enzyme has not yet been identified, perhaps due to the wide variety of enzymes that could fulfill this role. A study from 1995 suggested that a P450 monooxygenase is able to take on this role in tobacco (Leon et al., 1995), but further results were not published.

In Arabidopsis, the number of $P A L$ homologs is a modest four. Single and multiple mutants for these genes were extensively studied. The generated double and triple mutants showed no difference compared to WT plants in their basal SA content nor upon infection with Pseudomonas syringae pv tomato DC3000 (Pst DC3000). In the quadruple mutants, basal and pathogeninduced SA levels were $25 \%$ and $50 \%$ of that of WT, respectively. The quadruple mutants were also more susceptible than WT to Pst DC3000 (Huang et al., 2010). However, pal quadruple mutants showed developmental defects. This might cause ICSderived SA biosynthesis to be impaired and these mutants are therefore not ideal for studying $P A L$ contribution to SA biosynthesis in Arabidopsis (Huang et al., 2010).

The rice $P A L$ genes have been extensively studied for their role in stress responses (Giberti et al., 2012; Tonnessen et al., 2015; Li et al., 2018; Yu et al., 2018; Fang et al., 2019). Nine rice genes have been annotated as PALs. However, PAL9 was later shown to possess tyrosine aminomutase activity, hence its recent renaming as TAM1 (Yan et al., 2015). Discoveries like this make it questionable whether all of the other eight genes possess PAL activity. PAL 1-7 genes co-localize with disease resistance QTLs, indicating their role in plant defense (Tonnessen et al., 2015). Nevertheless, some $P A L$ genes are more involved in rice defense than others. Pal6 knock-out rice plants have a $70-77 \%$ decrease in PAL activity and show an increased susceptibility 
TABLE 1 | Exemplary genes involved in the biosynthesis of salicylic acid.

\begin{tabular}{|c|c|c|c|c|}
\hline Gene & Organism & Copy number & Function & Plant mutant phenotype \\
\hline At/CS & $\begin{array}{l}\text { Arabidopsis } \\
\text { thaliana }\end{array}$ & 2 & Isochorismate synthase, conversion of chorismate to isochorismate & $\begin{array}{l}\text { ics 1: severely reduced basal SA level } \\
\text { ics2: no significant change of basal SA level } \\
\text { ics1 ics2: severely reduced basal SA level } \\
\text { Garcion et al., } 2008\end{array}$ \\
\hline Os/CS & Oryza sativa & 1 & Isochorismate synthase, conversion of chorismate to isochorismate & / \\
\hline AtPAL & $\begin{array}{l}\text { Arabidopsis } \\
\text { thaliana }\end{array}$ & 4 & $\begin{array}{l}\text { Phenylalanine ammonia-lyase, conversion of phenylalanine to } \\
\text { trans-cinnamic acid }\end{array}$ & $\begin{array}{l}\text { pal1 pal2 pal3/4: no significant change of } \\
\text { SA accumulation } \\
\text { pal1 pal2 pal3 pal4: severely reduced basal } \\
\text { and induced SA levels } \\
\text { Huang et al., } 2010\end{array}$ \\
\hline OSPAL & Oryza sativa & 8 & $\begin{array}{l}\text { Phenylalanine ammonia-lyase, conversion of phenylalanine to } \\
\text { trans-cinnamic acid }\end{array}$ & $\begin{array}{l}\text { pal4: homozygous mutant lethal, } \\
\text { heterozygous mutants show increased } \\
\text { susceptibility to pathogens } \\
\text { pal6 }(=\text { pal/*): severely reduced SA } \\
\text { accumulation } \\
\quad \text { Duan et al., 2014; Tonnessen et al., } 2015\end{array}$ \\
\hline AtAlM1 & $\begin{array}{l}\text { Arabidopsis } \\
\text { thaliana }\end{array}$ & 1 & $\begin{array}{l}\text { beta-oxidation multifunctional protein, conversion of trans-cinnamic } \\
\text { acid to benzoic acid }\end{array}$ & $\begin{array}{l}\text { aim1: abnormal inflorescence, no } \\
\text { information about SA levels } \\
\text { Richmond and Bleecker, } 1999\end{array}$ \\
\hline OsAIM1 & Oryza sativa & 1 & $\begin{array}{l}\text { beta-oxidation multifunctional protein, conversion of trans-cinnamic } \\
\text { acid to benzoic acid }\end{array}$ & $\begin{array}{l}\text { aim1: short root phenotype, severely } \\
\text { reduced SA accumulation } \\
\qquad \text { Xu et al., } 2017\end{array}$ \\
\hline PBS3 & $\begin{array}{l}\text { Arabidopsis } \\
\text { thaliana }\end{array}$ & 1 & $\begin{array}{l}\text { Glutamate amidotransferase, conjugation of glutamate to isochorismate } \\
\text { to produce isochorismate-9-glutamate }\end{array}$ & $\begin{array}{r}\text { pbs3: severely reduced SA accumulation } \\
\text { Rekhter et al., } 2019\end{array}$ \\
\hline EDS5 & $\begin{array}{l}\text { Arabidopsis } \\
\text { thaliana }\end{array}$ & 1 & $\begin{array}{l}\text { Isochorismate transporter, transports isochorismate from chloroplast to } \\
\text { cytosol }\end{array}$ & / \\
\hline EPS1 & $\begin{array}{l}\text { Arabidopsis } \\
\text { thaliana }\end{array}$ & 1 & $\begin{array}{l}\text { ENHANCED PSEUDOMONAS SUSCEPTIBILITY 1, conversion of } \\
\text { isochorismate-9-glutamate to salicylic acid and } \\
\text { 2-hydroxy-acryloyl-N-glutamate }\end{array}$ & $\begin{array}{r}\text { eps 1: increased susceptibility to pathogens } \\
\text { Zheng et al., } 2009\end{array}$ \\
\hline PmsB & $\begin{array}{l}\text { Pseudomonas } \\
\text { species }\end{array}$ & 1 & $\begin{array}{l}\text { Isochorismate pyruvate-lyase, conversion of isochorismate to salicylic } \\
\text { acid and pyruvate }\end{array}$ & / \\
\hline PmsC & $\begin{array}{l}\text { Pseudomonas } \\
\text { species }\end{array}$ & 1 & Isochorismate synthase, conversion of chorismate to isochorismate & / \\
\hline
\end{tabular}

Above black separation: plant genes; below black separation: bacterial genes. *PAL6 from Duan et al. (2014) has the same locus number as PAL4 from Tonnessen et al. (2015) (LOC_Os02g41680).

to $M$. oryzae, indicating the relative importance of PAL6. These pal6 plants have a $60 \%$ decrease in SA content, despite a 3 fold upregulation of ICS, indicating that the PAL pathway is the main production pathway for SA in rice (Duan et al., 2014). PAL6 of Duan et al. (2014) is the same gene as PAL4 of Tonnessen et al. (2015). Heterozygous mutant pal4 plants (Tonnessen et al., 2015), which show a greater than twofold drop in PAL4 transcript level compared to WT, were more susceptible to $X$. oryzae pv. oryzae and to $R$. solani. They also show a highly induced PAL2 expression, while PAL6 expression is reduced [PAL gene numbering according to Tonnessen et al. (2015)]. These observations highlight the complex interplay between the different $P A L$ genes upon pathogen infection and suggest genespecific $P A L$ induction upon infection with a distinct pathogen (Tonnessen et al., 2015).

An abnormal inflorescence meristem1 (aim1) mutant was identified in Arabidopsis (Richmond and Bleecker, 1999). Arabidopsis has another gene (MFP2) that is homologous to AIM1, with a similar beta-oxidation function (Richmond and Bleecker, 1999). AIM1 has been shown to be necessary in
Arabidopsis for the production of $\mathrm{BA}$, a precursor of SA (Bussell et al., 2014). This makes it plausible that AIM1 is in large part responsible for the conversion of tCA to BA, which renders it a key enzyme in the PAL pathway. Yet, up to this point, no studies on SA levels in AIM1-deficient Arabidopsis plants have been published. Recently, a rice plant with reduced root meristem was identified with a mutation in the ABNORMAL INFLORESCENCE MERISTEM 1 (AIM1) gene (Xu et al., 2017). Rice panicles remained relatively normal, suggesting AIM1 has a different role than in Arabidopsis. Aim1 rice mutants only have a $30 \%$ of the SA levels in roots, compared to WT plants. Furthermore, they show a 2-fold decrease in BA content and a 6 -fold increase in t-coumaric acid (tCA), a precursor to BA. This indicates that AIM1 takes part in catalyzing the conversion of tCA to $\mathrm{BA}$ in rice. This makes it an interesting target for future research. Unfortunately, infection assays have not yet been performed on aim 1 rice plants. It should be noted that there are three more members in the rice $M F P$ family, which could partly contribute to the conversion of tCA to BA. 
Plant SA biosynthesis pathway preference has recently been reviewed by Hartmann and Zeier (2019). The few other studied plant species also show dominance of either the ICS or the PAL pathway for their SA production (Coquoz et al., 1998; Ogawa et al., 2006; Chang et al., 2008; Hao et al., 2018). Nevertheless, soybean (Glycine max), which has two ICS and five $P A L$ homologs, shows equally important roles for the ICS and PAL pathway in its SA accumulation. When infected with P. syringae pv. glycinea (Psg) or Phytophthora sojae, a threefold increase in SA is observed. Silencing of either the $P A L$ or the ICS pathway resulted in significantly reduced levels of SA accumulation upon pathogen infection. Furthermore, these silenced plants were more susceptible to infection by either of these pathogens (Shine et al., 2016).

\section{PATHOGENS INTERFERING WITH SA BIOSYNTHESIS}

Several pathogen effectors have been identified affecting SA levels and signaling. $P$. sojae and Verticillium dahliae secrete isochorismatases when infecting Arabidopsis and cotton (Gossypium hirsutum L.). Isochorismatase converts IC to 2,3dihydro-2,3-dihydroxybenzoate (DDHB), depleting IC as SA precursor, and consequently decreasing SA production. These effectors are necessary for full pathogenesis in the plant (Liu et al., 2014). Several plant-parasitic nematode species also produce isochorismatases (Bauters et al., 2014). Plant-parasitic nematodes also secrete CM (Haegeman et al., 2013), that can divert chorismate away from the ICS pathway, thus limiting SA accumulation (Wang et al., 2018). In maize, the fungus Ustilago maydis also secretes CM (Djamei et al., 2011). This enzyme has been identified in various plant pathogens, and loss-of-function mutants show a decreased pathogenicity. Both CM and ICM divert metabolites away from the ICS pathway, which could be an indication for its general importance upon pathogen infection. A different approach is the breakdown of SA in the plant. U. maydis can express a salicylate hydroxylase (Shy1), which is not secreted. Although this enzyme degrades SA, it has not yet been linked with virulence (Rabe et al., 2013). When a bacterial NahG gene is expressed in tobacco, it has been shown to effectively degrade SA (Gaffney et al., 1993). Fusarium graminearum also produces a salicylate hydroxylase $(\mathrm{FgNahG})$, and wheat plants infected with a fgnahg mutant strain showed fewer disease symptoms and a higher level of SA accumulation in wheat spikes compared to infection with WT F. graminearum

\section{REFERENCES}

Abreu, M. E., and Munne-Bosch, S. (2009). Salicylic acid deficiency in NahG transgenic lines and sid2 mutants increases seed yield in the annual plant Arabidopsis thaliana. J. Exp. Bot. 60, 1261-1271. doi: 10.1093/jxb/ern363

Arent, S., Christensen, C. E., Pye, V. E., Norgaard, A., and Henriksen, A. (2010). The multifunctional protein in peroxisomal beta-oxidation: structure and substrate specificity of the Arabidopsis thaliana protein MFP2. J. Biol. Chem. 285, 24066-24077. doi: 10.1074/jbc.M110. 106005
(Qi et al., 2019). In addition, pathogens do not only interfere with SA accumulation but can also disrupt SA signaling pathways (Tanaka et al., 2015).

\section{DISCUSSION}

Publications often generalize that the ICS pathway is responsible for basal and pathogen-induced SA accumulation in plants, and this is based on data from Arabidopsis (Djamei et al., 2011; Choi et al., 2015; Qi et al., 2018). While this seems to hold true, at least in part, for Arabidopsis, a general answer for all plant species does not seem that clear-cut. Some plants seem to mainly use the PAL pathway instead of the ICS pathway for SA biosynthesis. Unraveling the details of the pathway becomes challenging because some of the enzymes involved remain unidentified to this day, and different plants seems to have evolved in different directions. Furthermore, the high copy number of the PAL and $C M$ genes in the genome renders these hard to study, and inactivation of one gene can influence activity of the others.

The last step in the PAL pathway is thought to be catalyzed by a benzoic acid-2-hydroxylase (BA2H). Yet, its existence has only been indirectly shown (Sawada et al., 2006). It is still possible that the conversion from Phe to SA also happens via an alternative route, as shown by several isotope feeding studies (Klämbt, 1962; El-Basyouni et al., 1964; Chadha and Brown, 1974).

While the PBS3 gene has been identified in Arabidopsis, it has not been described in any other plant species. As it was reported that barley ics mutants do not show a difference in SA levels, we could speculate that plants that predominantly use the PAL pathway for SA biosynthesis do not contain an active PBS3 gene and solely use ICS for the biosynthesis of other metabolites (Qin et al., 2019).

\section{AUTHOR CONTRIBUTIONS}

HL and GG designed the content of the manuscript. HL wrote the manuscript. GG and LB revised and corrected the manuscript. All authors read and approved the final manuscript.

\section{ACKNOWLEDGMENTS}

We would like to thank the Research Foundation Flanders FWO for financial support (FWO grant 3G009829W).

Barros, J., Serrani-Yarce, J. C., Chen, F., Baxter, D., Venables, B. J., and Dixon, R. A. (2016). Role of bifunctional ammonia-lyase in grass cell wall biosynthesis. Nat. Plants 2:16050. doi: 10.1038/nplants.2016.50

Bauters, L., Haegeman, A., Kyndt, T., and Gheysen, G. (2014). Analysis of the transcriptome of Hirschmanniella oryzae to explore potential survival strategies and host-nematode interactions. Mol. Plant Pathol. 15, 352-363. doi: 10.1111/ mpp.12098

Bussell, J. D., Reichelt, M., Wiszniewski, A. A., Gershenzon, J., and Smith, S. M. (2014). Peroxisomal ATP-binding cassette transporter COMATOSE and the multifunctional protein abnormal INFLORESCENCE MERISTEM are required 
for the production of benzoylated metabolites in Arabidopsis seeds. Plant Physiol. 164, 48-54. doi: 10.1104/pp.113.229807

Cass, C. L., Peraldi, A., Dowd, P. F., Mottiar, Y., Santoro, N., Karlen, S. D., et al. (2015). Effects of PHENYLALANINE AMMONIA LYASE (PAL) knockdown on cell wall composition, biomass digestibility, and biotic and abiotic stress responses in Brachypodium. J. Exp. Bot. 66, 4317-4335. doi: 10.1093/jxb/ erv269

Catinot, J., Buchala, A., Abou-Mansour, E., and Metraux, J. P. (2008). Salicylic acid production in response to biotic and abiotic stress depends on isochorismate in Nicotiana benthamiana. FEBS Lett. 582, 473-478. doi: 10.1016/j.febslet.2007.12. 039

Chadha, K. C., and Brown, S. A. (1974). Biosynthesis of phenolic acids in tomato plants infected with Agrobacterium tumefaciens. Canad. J. Bot. 52, 2041-2047.

Chang, A., Lim, M. H., Lee, S. W., Robb, E. J., and Nazar, R. N. (2008). Tomato phenylalanine ammonia-lyase gene family, highly redundant but strongly underutilized. J. Biol. Chem. 283, 33591-33601. doi: 10.1074/jbc.M804428200

Chen, L., Wang, W. S., Wang, T., Meng, X. F., Chen, T. T., Huang, X. X., et al. (2019). Methyl salicylate glucosylation regulates plant defense signaling and systemic acquired resistance. Plant Physiol. 180, 2167-2181. doi: 10.1104/pp. 19.00091

Choi, C., Hwang, S. H., Fang, I. R., Kwon, S. I., Park, S. R., Ahn, I., et al. (2015). Molecular characterization of Oryza sativa WRKY6, which binds to W-boxlike element 1 of the Oryza sativa pathogenesis-related (PR) 10a promoter and confers reduced susceptibility to pathogens. New Phytol. 208, 846-859. doi: $10.1111 /$ nph. 13516

Coquoz, J. L., Buchala, A., and Metraux, J. P. (1998). The biosynthesis of salicylic acid in potato plants. Plant Physiol. 117, 1095-1101.

Dean, J. V., Shah, R. P., and Mohammed, L. A. (2003). Formation and vacuolar localization of salicylic acid glucose conjugates in soybean cell suspension cultures. Physiol. Plant. 118, 328-336.

Dempsey, D. A., Vlot, A. C., Wildermuth, M. C., and Klessig, D. F. (2011). Salicylic acid biosynthesis and metabolism. Arabid. Book 9:e0156. doi: 10.1199/tab.0156

Dixon, R. A., and Paiva, N. L. (1995). Stress-induced phenylpropanoid metabolism. Plant Cell 7, 1085-1097.

Djamei, A., Schipper, K., Rabe, F., Ghosh, A., Vincon, V., Kahnt, J., et al. (2011). Metabolic priming by a secreted fungal effector. Nature 478, 395-398. doi: 10.1038/nature10454

Duan, L., Liu, H., Li, X., Xiao, J., and Wang, S. (2014). Multiple phytohormones and phytoalexins are involved in disease resistance to Magnaporthe oryzae invaded from roots in rice. Physiol. Plant. 152, 486-500. doi: 10.1111/ppl.12192

El-Basyouni, S. Z., Chen, D., Ibrahim, R., Neish, A., and Towers, G. (1964). The biosynthesis of hydroxybenzoic acids in higher plants. Phytochemistry 3, 485-492.

Fang, C., Li, L., Zhang, P., Wang, D., Yang, L., Reza, B. M., et al. (2019). Lsi1 modulates the antioxidant capacity of rice and protects against ultraviolet- $B$ radiation. Plant Sci. Int. J. Exp. Plant Biol. 278, 96-106. doi: 10.1016/j.plantsci. 2018.10.003

Gaffney, T., Friedrich, L., Vernooij, B., Negrotto, D., Nye, G., Uknes, S., et al. (1993). Requirement of salicylic Acid for the induction of systemic acquired resistance. Science (New York, N.Y.) 261, 754-756.

Garcion, C., Lohmann, A., Lamodiere, E., Catinot, J., Buchala, A., Doermann, P., et al. (2008). Characterization and biological function of the ISOCHORISMATE SYNTHASE2 gene of Arabidopsis. Plant Physiol. 147, 1279-1287. doi: 10.1104/ pp.108.119420

Giberti, S., Bertea, C. M., Narayana, R., Maffei, M. E., and Forlani, G. (2012). Two phenylalanine ammonia lyase isoforms are involved in the elicitor-induced response of rice to the fungal pathogen Magnaporthe oryzae. J. Plant Physiol. 169, 249-254. doi: 10.1016/j.jplph.2011.10.008

Haegeman, A., Bauters, L., Kyndt, T., Rahman, M. M., and Gheysen, G. (2013). Identification of candidate effector genes in the transcriptome of the rice root knot nematode Meloidogyne graminicola. Mol. Plant Pathol. 14, 379-390.

Hao, Q., Wang, W., Han, X., Wu, J., Lyu, B., Chen, F., et al. (2018). Isochorismate-based salicylic acid biosynthesis confers basal resistance to Fusarium graminearum in barley. Mol. Plant Pathol. 19, 1995-2010.

Hartmann, M., and Zeier, J. (2019). N-hydroxypipecolic acid and salicylic acid: a metabolic duo for systemic acquired resistance. Curr. Opin. Plant Biol. 50, 44-57. doi: 10.1016/j.pbi.2019.02.006
Huang, J., Gu, M., Lai, Z., Fan, B., Shi, K., Zhou, Y. H., et al. (2010). Functional analysis of the Arabidopsis PAL gene family in plant growth, development, and response to environmental stress. Plant Physiol. 153, 1526-1538. doi: 10.1104/ pp. 110.157370

Huang, W., Wang, Y., Li, X., and Zhang, Y. (2020). Biosynthesis and regulation of salicylic acid and N-hydroxypipecolic acid in plant immunity. Mol. Plant 13, 31-41. doi: 10.1016/j.molp.2019.12.008

Jagadeeswaran, G., Raina, S., Acharya, B. R., Maqbool, S. B., Mosher, S. L., Appel, H. M., et al. (2007). Arabidopsis GH3-LIKE DEFENSE GENE 1 is required for accumulation of salicylic acid, activation of defense responses and resistance to Pseudomonas syringae. Plant J. Cell Mol. Biol. 51, 234-246.

Kim, D. S., and Hwang, B. K. (2014). An important role of the pepper phenylalanine ammonia-lyase gene (PAL1) in salicylic acid-dependent signalling of the defence response to microbial pathogens. J. Exp. Bot. 65, 2295-2306. doi: 10. 1093/jxb/eru109

Klämbt, H. D. (1962). Conversion in plants of benzoic acid to salicylic acid and its Bd-glucoside. Nature 196, 491-491.

Lawton, K., Weymann, K., Friedrich, L., Vernooij, B., Uknes, S., and Ryals, J. (1995). Systemic acquired resistance in Arabidopsis requires salicylic acid but not ethylene. Mol. Plant Microbe Interact. MPMI 8, 863-870.

Lee, M. W., Lu, H., Jung, H. W., and Greenberg, J. T. (2007). A key role for the Arabidopsis WIN3 protein in disease resistance triggered by Pseudomonas syringae that secrete AvrRpt2. Mol. Plant Microbe Interact. MPMI 20, 11921200.

Leon, J., Shulaev, V., Yalpani, N., Lawton, M. A., and Raskin, I. (1995). Benzoic acid 2-hydroxylase, a soluble oxygenase from tobacco, catalyzes salicylic acid biosynthesis. Proc. Natl. Acad. Sci. U.S.A. 92, 10413-10417.

Li, X., He, Y., Xie, C., Zu, Y., Zhan, F., Mei, X., et al. (2018). Effects of UV-B radiation on the infectivity of Magnaporthe oryzae and rice diseaseresistant physiology in Yuanyang terraces. Photochem. Photobiol. Sci. Off. J. Eur. Photochem. Assoc. Eur. Soc. Photobiol. 17, 8-17.

Liu, Q., Li, X., Yan, S., Yu, T., Yang, J., Dong, J., et al. (2018). OsWRKY67 positively regulates blast and bacteria blight resistance by direct activation of PR genes in rice. BMC Plant Biol. 18:257. doi: 10.1186/s12870-018-1479-y

Liu, T., Song, T., Zhang, X., Yuan, H., Su, L., Li, W., et al. (2014). Unconventionally secreted effectors of two filamentous pathogens target plant salicylate biosynthesis. Nat. Commun. 5:4686. doi: 10.1038/ncomms5686

Liu, X. Q., Bai, X. Q., Qian, Q., Wang, X. J., Chen, M. S., and Chu, C. C. (2005). OsWRKY03, a rice transcriptional activator that functions in defense signaling pathway upstream of OsNPR1. Cell Res. 15, 593-603.

Mackelprang, R., Okrent, R. A., and Wildermuth, M. C. (2017). Preference of Arabidopsis thaliana GH3.5 acyl amido synthetase for growth versus defense hormone acyl substrates is dictated by concentration of amino acid substrate aspartate. Phytochemistry 143, 19-28. doi: 10.1016/j.phytochem.2017.07.001

Maruri-Lopez, I., Aviles-Baltazar, N. Y., Buchala, A., and Serrano, M. (2019). Intra and extracellular journey of the phytohormone salicylic acid. Front. Plant Sci. 10:423. doi: 10.3389/fpls.2019.00423

Mercado-Blanco, J., Van Der Drift, K. M., Olsson, P. E., Thomas-Oates, J. E., Van Loon, L. C., and Bakker, P. A. (2001). Analysis of the pmsCEAB gene cluster involved in biosynthesis of salicylic acid and the siderophore pseudomonine in the biocontrol strain Pseudomonas fluorescens WCS374. J. Acteriol. 183, 1909-1920.

Nahar, K., Kyndt, T., De Vleesschauwer, D., Hofte, M., and Gheysen, G. (2011). The jasmonate pathway is a key player in systemically induced defense against root knot nematodes in rice. Plant Physiol. 157, 305-316. doi: 10.1104/pp.111. 177576

Nawrath, C., Heck, S., Parinthawong, N., and Metraux, J. P. (2002). EDS5, an essential component of salicylic acid-dependent signaling for disease resistance in Arabidopsis, is a member of the MATE transporter family. Plant Cell 14, $275-286$.

Nawrath, C., and Metraux, J. P. (1999). Salicylic acid induction-deficient mutants of Arabidopsis express PR-2 and PR-5 and accumulate high levels of camalexin after pathogen inoculation. Plant Cell 11, 1393-1404.

Nobuta, K., Okrent, R. A., Stoutemyer, M., Rodibaugh, N., Kempema, L., Wildermuth, M. C., et al. (2007). The GH3 acyl adenylase family member PBS3 regulates salicylic acid-dependent defense responses in Arabidopsis. Plant Physiol. 144, 1144-1156. 
Ogawa, D., Nakajima, N., Seo, S., Mitsuhara, I., Kamada, H., and Ohashi, Y. J. P. B. (2006). The phenylalanine pathway is the main route of salicylic acid biosynthesis in Tobacco mosaic virus-infected tobacco leaves. Plant Biotechnol. 23, 395-398.

Pokotylo, I., Kravets, V., and Ruelland, E. (2019). salicylic acid binding proteins (SABPs): the hidden forefront of salicylic acid signalling. Int. J. Mol. Sci. 20:4377.

Qi, G., Chen, J., Chang, M., Chen, H., Hall, K., Korin, J., et al. (2018). Pandemonium breaks out: disruption of salicylic acid-mediated defense by plant pathogens. Mol. Plant 11, 1427-1439. doi: 10.1016/j.molp.2018. 10.002

Qi, P.-F., Zhang, Y.-Z., Liu, C.-H., Chen, Q., Guo, Z.-R., Wang, Y., et al. (2019). Functional analysis of FgNahG clarifies the contribution of salicylic acid to wheat (Triticum aestivum) resistance against fusarium head blight. Toxins 11:59. doi: 10.3390/toxins11020059

Qin, Y., Torp, A. M., Glauser, G., Pedersen, C., Rasmussen, S. K., and Thordal-Christensen, H. (2019). Barley isochorismate synthase mutant is phylloquinone-deficient, but has normal basal salicylic acid level. Plant Signal. Behav. 14:1671122. doi: 10.1080/15592324.2019.1671122

Rabe, F., Ajami-Rashidi, Z., Doehlemann, G., Kahmann, R., and Djamei, A. (2013). Degradation of the plant defence hormone salicylic acid by the biotrophic fungus Ustilago maydis. Mol. Microbiol. 89, 179-188. doi: 10.1111/mmi.12269

Reichert, A. I., He, X. Z., and Dixon, R. A. (2009). Phenylalanine ammonia-lyase (PAL) from tobacco (Nicotiana tabacum): characterization of the four tobacco PAL genes and active heterotetrameric enzymes. Biochem. J. 424, 233-242. doi: 10.1042/BJ20090620

Rekhter, D., Lüdke, D., Ding, Y., Feussner, K., Zienkiewicz, K., Lipka, V., et al. (2019). Isochorismate-derived biosynthesis of the plant stress hormone salicylic acid. Science 365, 498-502.

Richmond, T. A., and Bleecker, A. B. (1999). A defect in beta-oxidation causes abnormal inflorescence development in Arabidopsis. Plant Cell 11, 1911-1924.

Rosler, J., Krekel, F., Amrhein, N., and Schmid, J. (1997). Maize phenylalanine ammonia-lyase has tyrosine ammonia-lyase activity. Plant Physiol. 113, 175179.

Rylott, E. L., Eastmond, P. J., Gilday, A. D., Slocombe, S. P., Larson, T. R., Baker, A., et al. (2006). The Arabidopsis thaliana multifunctional protein gene (MFP2) of peroxisomal beta-oxidation is essential for seedling establishment. Plant J. Cell Mol. Biol. 45, 930-941.

Sawada, H., Shim, I.-S., and Usui, K. J. P. S. (2006). Induction of benzoic acid 2hydroxylase and salicylic acid biosynthesis-modulation by salt stress in rice seedlings. Plant Sci. 171, 263-270.

Shine, M. B., Yang, J. W., El-Habbak, M., Nagyabhyru, P., Fu, D. Q., Navarre, D., et al. (2016). Cooperative functioning between phenylalanine ammonia lyase and isochorismate synthase activities contributes to salicylic acid biosynthesis in soybean. New Phytol. 212, 627-636. doi: 10.1111/nph.14078

Silverman, P., Seskar, M., Kanter, D., Schweizer, P., Metraux, J. P., and Raskin, I. (1995). Salicylic acid in rice (biosynthesis, conjugation, and possible role). Plant Physiol. 108, 633-639.

Snoeren, T. A., Mumm, R., Poelman, E. H., Yang, Y., Pichersky, E., and Dicke, M. (2010). The herbivore-induced plant volatile methyl salicylate negatively affects attraction of the parasitoid Diadegma semiclausum. J. Chem. Ecol. 36, 479-489. doi: 10.1007/s10886-010-9787-1

Tanaka, S., Han, X., and Kahmann, R. (2015). Microbial effectors target multiple steps in the salicylic acid production and signaling pathway. Front. Plant Sci. 6:349. doi: 10.3389/fpls.2015.00349
Tonnessen, B. W., Manosalva, P., Lang, J. M., Baraoidan, M., Bordeos, A., Mauleon, R., et al. (2015). Rice phenylalanine ammonia-lyase gene OsPAL4 is associated with broad spectrum disease resistance. Plant Mol. Biol. 87, 273-286. doi: 10. 1007/s11103-014-0275-9

Torrens-Spence, M. P., Bobokalonova, A., Carballo, V., Glinkerman, C. M., Pluskal, T., Shen, A., et al. (2019). PBS3 and EPS1 complete salicylic acid biosynthesis from isochorismate in Arabidopsis. Mol. Plant 12, 1577-1586.

Tripathi, D., Raikhy, G., and Kumar, D. (2019). Chemical elicitors of systemic acquired resistance-Salicylic acid and its functional analogs. Curr. Plant Biol. $17,48-59$.

Wang, X., Xue, B., Dai, J., Qin, X., Liu, L., Chi, Y., et al. (2018). A novel Meloidogyne incognita chorismate mutase effector suppresses plant immunity by manipulating the salicylic acid pathway and functions mainly during the early stages of nematode parasitism. Plant Pathol. 67, 1436-1448.

Wang, Y., and Liu, J. H. (2012). Exogenous treatment with salicylic acid attenuates occurrence of citrus canker in susceptible navel orange (Citrus sinensis Osbeck). J. Plant Physiol. 169, 1143-1149. doi: 10.1016/j.jplph.2012.03.018

White, R. F. (1979). Acetylsalicylic acid (aspirin) induces resistance to tobacco mosaic virus in tobacco. Virology 99, 410-412.

Xu, L., Zhao, H., Ruan, W., Deng, M., Wang, F., Peng, J., et al. (2017). Abnormal inflorescence meristem 1 functions in salicylic acid biosynthesis to maintain proper reactive oxygen species levels for root meristem activity in rice. Plant Cell 29, 560-574. doi: 10.1105/tpc.16.00665

Yan, J., Aboshi, T., Teraishi, M., Strickler, S. R., Spindel, J. E., Tung, C. W., et al. (2015). The tyrosine aminomutase TAM1 is required for beta-tyrosine biosynthesis in rice. Plant Cell 27, 1265-1278. doi: 10.1105/tpc.15.00058

Yokoo, S., Inoue, S., Suzuki, N., Amakawa, N., Matsui, H., Nakagami, H., et al. (2018). Comparative analysis of plant isochorismate synthases reveals structural mechanisms underlying their distinct biochemical properties. Biosci. Rep. 38:BSR20171457.

Yu, X. Z., Fan, W. J., Lin, Y. J., Zhang, F. F., and Gupta, D. K. (2018). Differential expression of the PAL gene family in rice seedlings exposed to chromium by microarray analysis. Ecotoxicology (Lond. Engl.) 27, 325-335. doi: 10.1007/ s10646-018-1897-5

Zhang, Y., and Li, X. (2019). Salicylic acid: biosynthesis, perception, and contributions to plant immunity. Curr. Opin. Plant Biol. 50, 29-36. doi: 10. 1016/j.pbi.2019.02.004

Zhao, X., Chen, S., Wang, S., Shan, W., Wang, X., Lin, Y., et al. (2019). Defensive responses of tea plants (Camellia sinensis) against tea green leafhopper attack: a multi-omics study. Front. Plant Sci. 10:1705. doi: 10.3389/fpls.2019.01705

Zheng, Z., Qualley, A., Fan, B., Dudareva, N., and Chen, Z. (2009). An important role of a BAHD acyl transferase-like protein in plant innate immunity. Plant J. 57, 1040-1053. doi: 10.1111/j.1365-313X.2008.03747.x

Conflict of Interest: The authors declare that the research was conducted in the absence of any commercial or financial relationships that could be construed as a potential conflict of interest.

Copyright (c) 2020 Lefevere, Bauters and Gheysen. This is an open-access article distributed under the terms of the Creative Commons Attribution License (CC BY). The use, distribution or reproduction in other forums is permitted, provided the original author(s) and the copyright owner(s) are credited and that the original publication in this journal is cited, in accordance with accepted academic practice. No use, distribution or reproduction is permitted which does not comply with these terms. 